

\title{
In Solitary Rabbits, Does the Presence or Absence of a Mirror Affect Stress, Fear and Anxiety?
}

A Knowledge Summary by

Rebecca Schofield RVN, BSc (Hons) ${ }^{1^{*}}$

\footnotetext{
${ }^{1}$ PDSA, Veterinary Client Services, Prospect House, North Hylton Road, Sunderland, SR5 3AD

*Corresponding Author (schofield.rebecca@pdsa.org.uk)
}

ISSN: 2396-9776

Published: 12 April 2019

in: Vol 4, Issue 2

DOI: http://dx.doi.org/10.18849/ve.v4i2.177

Reviewed by: Laura Dixon (PhD BSc) and Jackie Belle (RVN CertSAN CertFN CertVNES DipCABT DipESM Dip BR DipEnDv PTLLS BSC MSc)

Next Review Date: 12 April 2021 


\section{KNOWLEDGE SUMMARY}

\section{PICO question}

In solitary rabbits, does the presence or absence of a mirror affect stress, fear and anxiety?

\section{Clinical bottom line}

Four studies were reviewed in this knowledge summary. Despite the small number of papers available, the controlled trials and their methodologies provide strong evidence that the behavior of solitary laboratory rabbits is affected by the presence or absence of mirrors. This evidence also indicates an effect on their welfare.

The studies suggest that the presence of mirrors provides environmental enrichment and have a positive effect on the subjects health and welfare. However, it is also suggested that mirrors may have some detrimental physical and psychological effects for some individuals. There are also many gaps in the available research and these need to be addressed to give better insight into the effect of mirrors on rabbits.

Because of the current level of knowledge, clinical recommendations cannot be made at present on the use of mirrors in solitary rabbits to improve their veterinary care whilst hospitalised.

\section{Clinical Scenario}

Rabbits are social animals and require same species companionship in captivity. From recent rabbit CPD courses run by LagoLearn and The Rabbit Welfare Association \& Fund, the accepted gold standard of rabbit veterinary care is to also bring bonded companions into practice during periods of hospitalisation.

Mirrors have been successfully used and proven to reduce stress in other isolated social species; sheep (Parrott et al., 1988); cattle (Piller et al., 1999); horses (McAfee et al., 2002). Could mirrors help reduce stress in rabbits? Could the use of mirrors be advantageous for solitary housed rabbits in a veterinary practice, subsequently improving their recovery time, nursing care and welfare?

\section{The evidence}

The literature searches found four relevant papers (Jones \& Phillips, 2005; Dalle Zotte et al., 2008; Edgar \& Seaman, 2010; Reddi et al., 2011) that directly compared whether presence or absence of mirrors influenced rabbit behaviour. None of these directly measured stress, fear or anxiety, however all assessed preference for mirrors by observing rabbit behaviour instead. The quality of evidence was strong due to the use of controlled trials in all research papers. All studies suggested that in laboratory rabbits, mirrors had some welfare advantages. No evidence was found on the use of mirrors in a domesticated or veterinary setting. 


\begin{tabular}{|c|c|}
\hline \multicolumn{2}{|l|}{ Reddi et al. (2011) } \\
\hline Population: & $\begin{array}{l}\text { Weaned New Zealand White rabbits, weighing } 450-500 \mathrm{~g} \text { on a } \\
\text { private rabbit farm in Bangalore, India }\end{array}$ \\
\hline Sample size: & 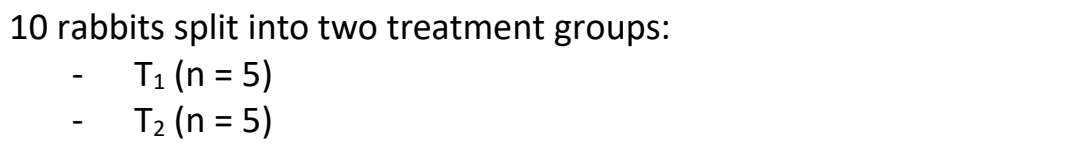 \\
\hline Intervention details: & 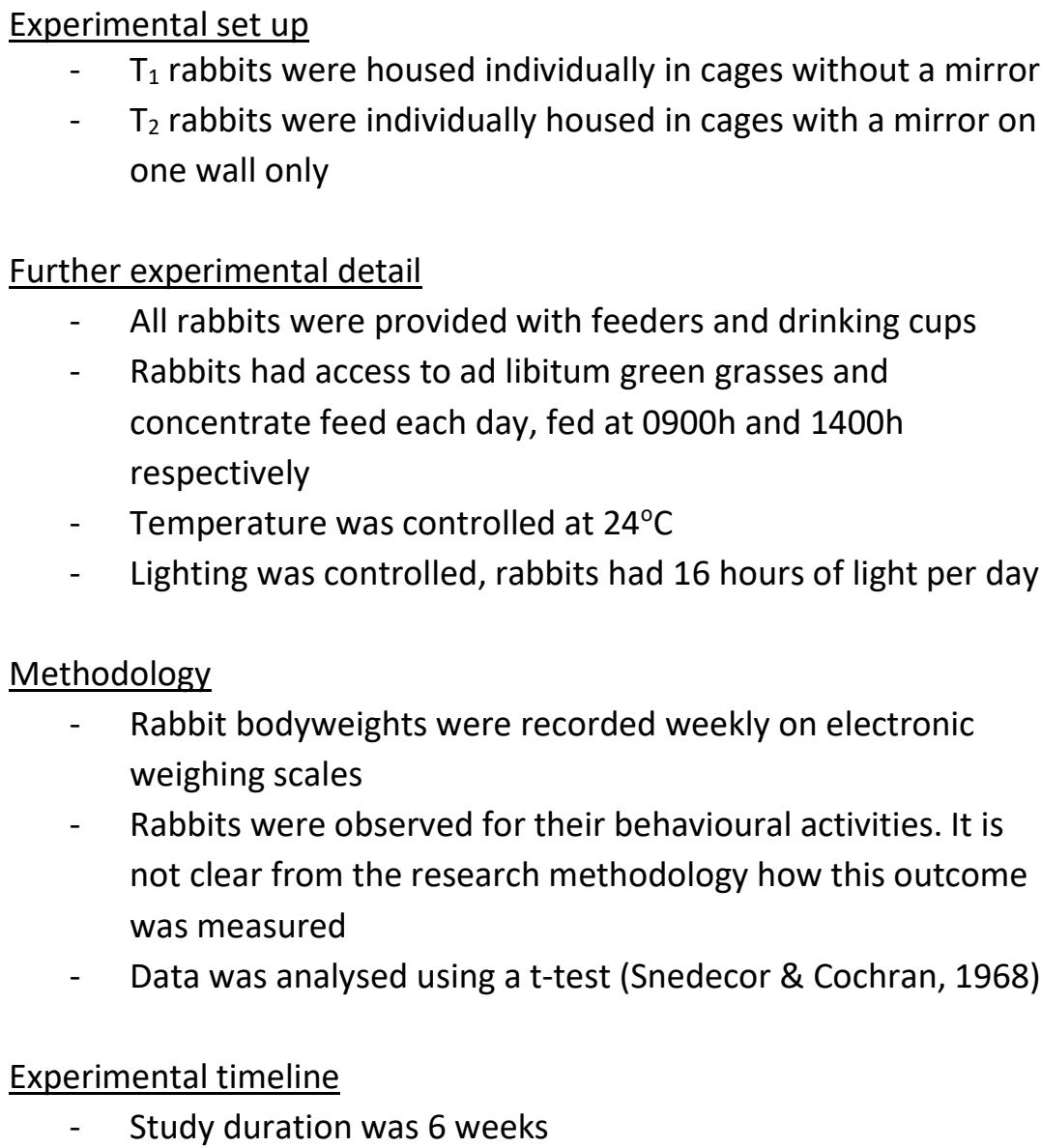 \\
\hline Study design: & Controlled trial \\
\hline Outcome studied: & $\begin{array}{l}\text { The influence of presence or absence of a mirror on: } \\
\text { - Growth performance including average daily and weekly } \\
\text { bodyweight gains } \\
\text { - Behaviour changes including; activities, performance, } \\
\text { feeding preferences, comfort and other notable behaviours } \\
\text { ex. scrabbling at the mirror }\end{array}$ \\
\hline $\begin{array}{l}\text { Main findings: } \\
\text { (relevant to PICO question): }\end{array}$ & 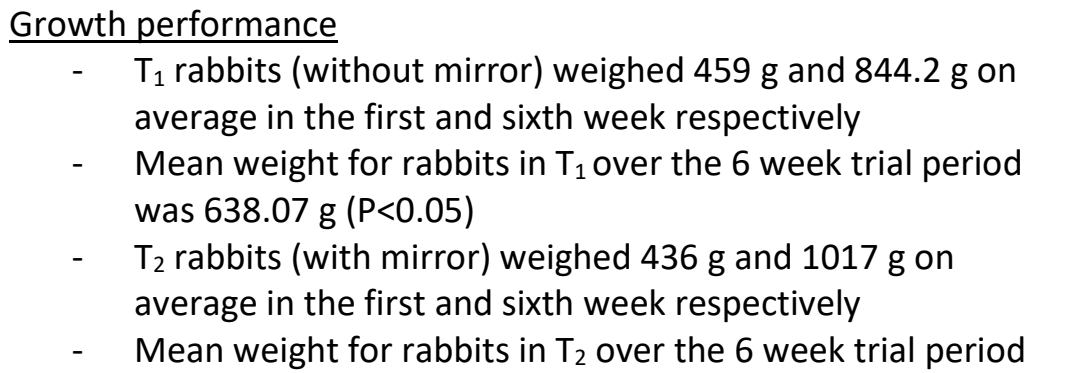 \\
\hline
\end{tabular}




\begin{tabular}{|c|c|}
\hline & $\begin{array}{l}\text { was } 729.87 \mathrm{~g}(\mathrm{P}<0.05) \\
\text { - } \text { Rabbits individually housed with a mirror in their cage had } \\
\text { higher average weight gains throughout the trial period } \\
\text { Behaviour changes } \\
-\quad \mathrm{T}_{2} \text { rabbits were more active } \\
-\quad \mathrm{T}_{2} \text { rabbits tried to look at the mirror most of the time, } \\
\text { including when feeding } \\
-\quad \mathrm{T}_{2} \text { rabbits consumed all feed without residues } \\
-\quad \mathrm{T}_{2} \text { rabbits preferred the cage side and to remain in } \\
\text { comfortable positions }\end{array}$ \\
\hline Limitations: & $\begin{array}{l}\text { - Small sample size } \\
\text { - } \quad \text { Only one breed of rabbit used } \\
\text { - Increase in bodyweight may not mean better welfare for the } \\
\text { rabbits. A barren experimental environment could mean } \\
\text { that feeding is the only enrichment and stimulation received } \\
\text { each day, so rabbits may have spent more time eating in } \\
\text { general as that was the only activity available } \\
\text { - Frequency of behaviour (activity, looking into the mirror } \\
\text { whilst eating) for } T_{2} \text { rabbits housed individually with a mirror } \\
\text { remained significant until decreasing after } 2 \text { weeks into the } \\
\text { trial. This could be due to habituation to the mirror as the } \\
\text { rabbit did not receive confirmatory cues that the image was } \\
\text { a conspecific } \\
\text { Limited insight into methodology for behavioural } \\
\text { measurement and assessment so unable to gain insight into } \\
\text { how the data was acquired }\end{array}$ \\
\hline
\end{tabular}

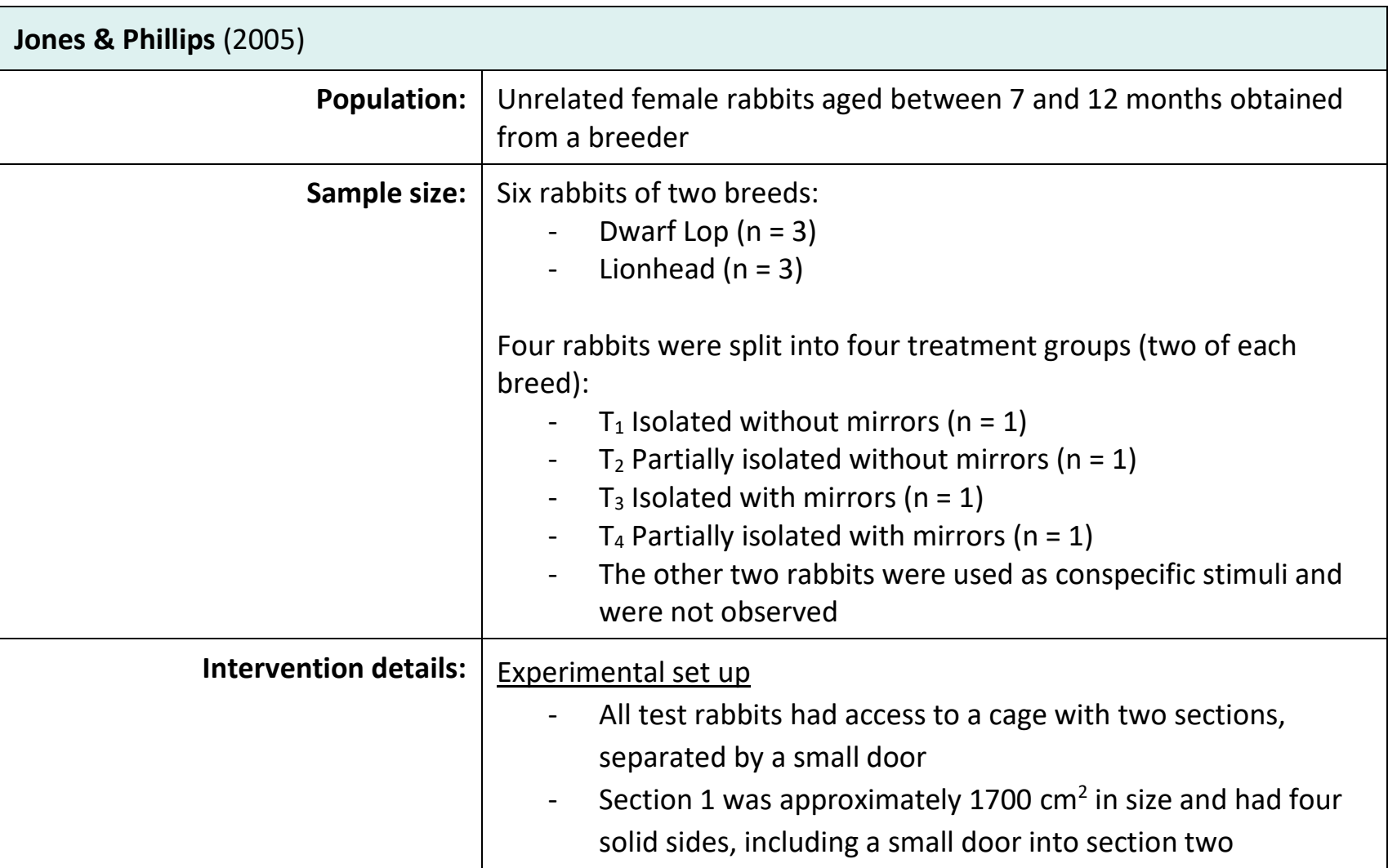




\begin{tabular}{|c|c|}
\hline & 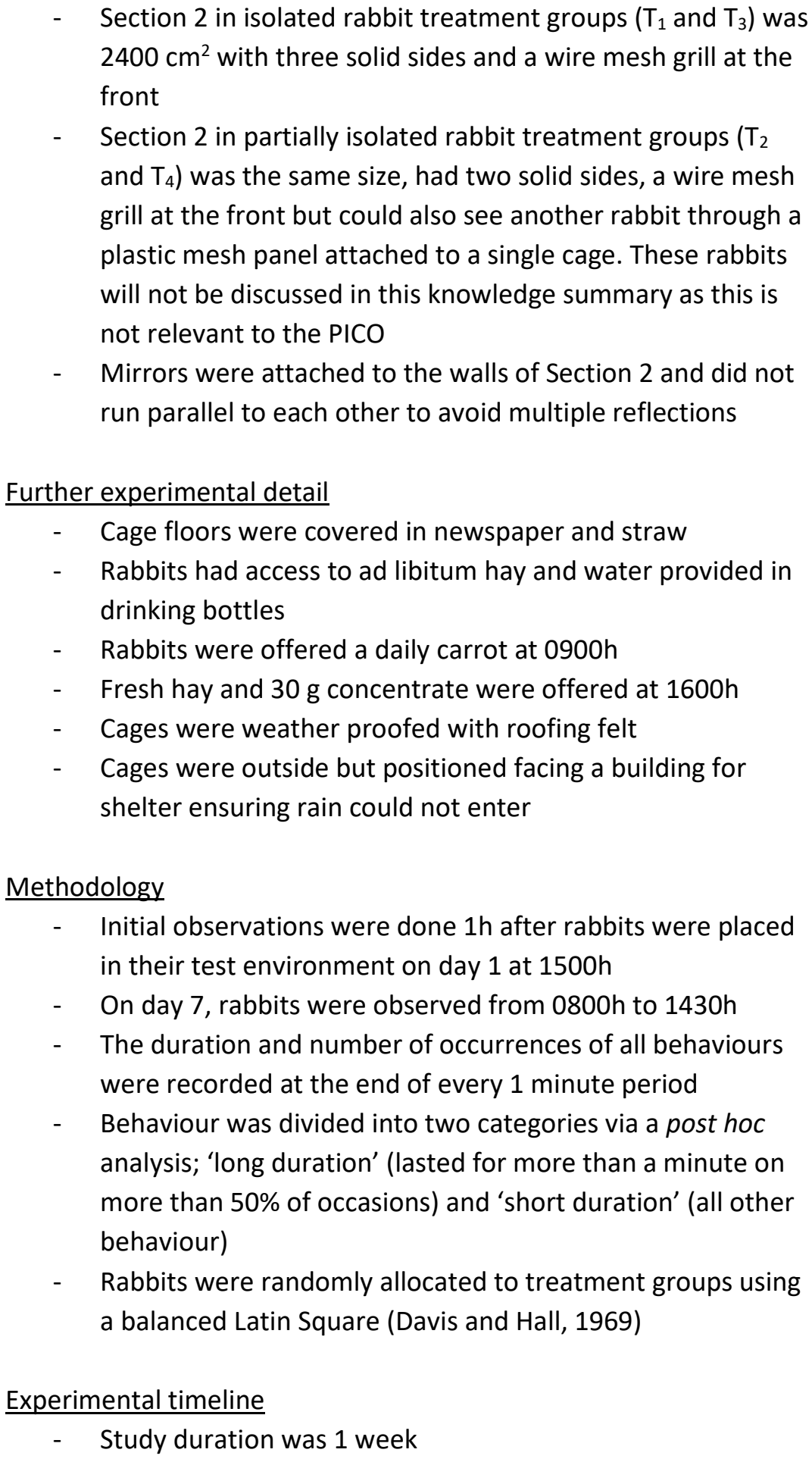 \\
\hline Study design: & Randomised controlled trial \\
\hline Outcome studied: & $\begin{array}{l}\text { The effects of provision or absence of mirrors on behaviour duration } \\
\text { and frequency of behaviour exhibition over time. The time periods } \\
\text { observed were: } \\
\begin{array}{l}\text { - Initial response } \\
\text { - Response over time (comparison between day } 1 \text { and day } 7 \text { ) }\end{array}\end{array}$ \\
\hline $\begin{array}{l}\text { Main findings: } \\
\text { (relevant to PICO question): }\end{array}$ & $\begin{array}{l}\text { Initial response } \\
\begin{array}{ll}\text { Rabbits housed with a mirror showed some alert behaviour, } \\
\text { whereas rabbits without a mirror did not }\end{array}\end{array}$ \\
\hline
\end{tabular}




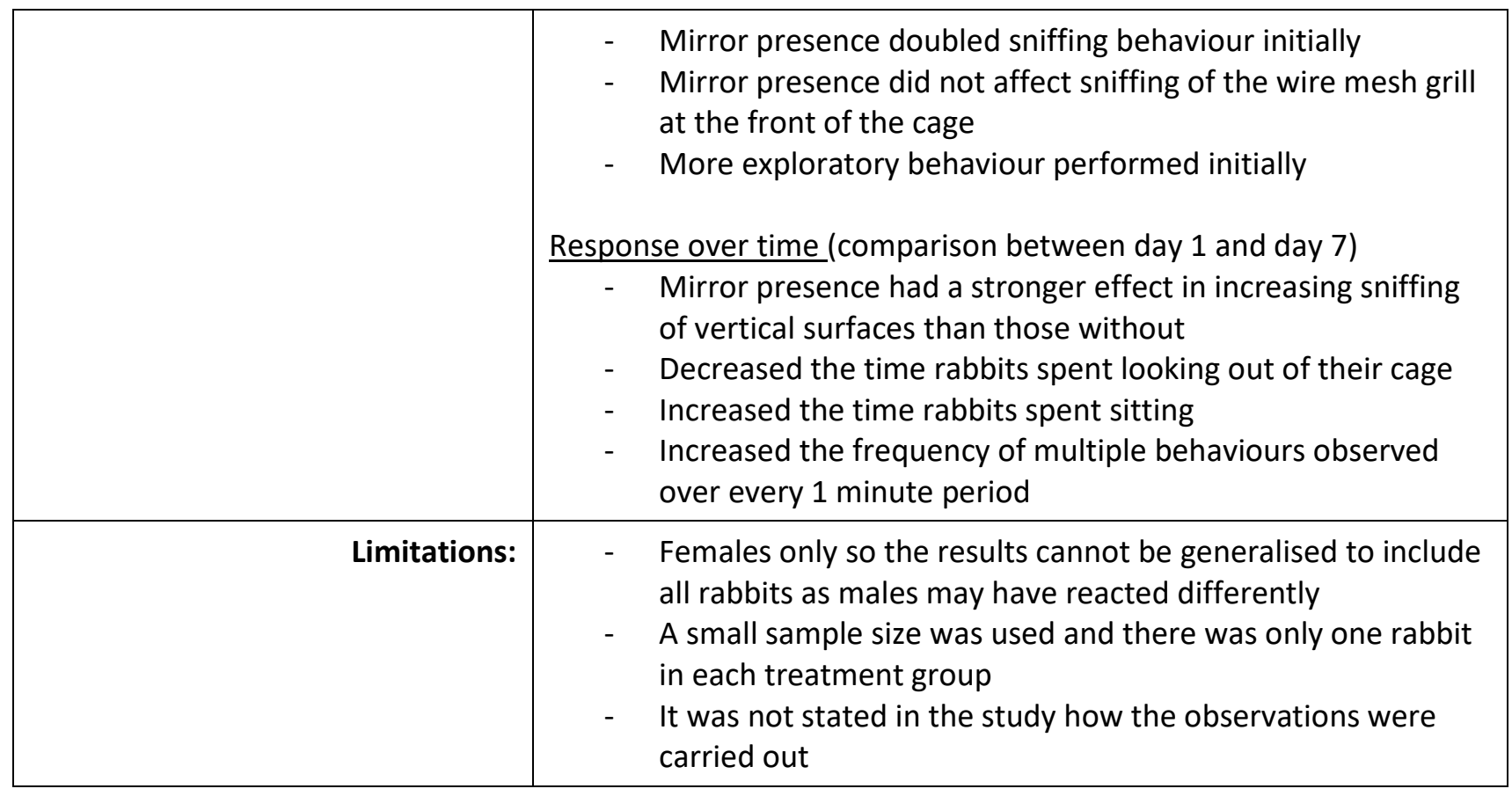

Edgar \& Seaman (2010)

\begin{tabular}{|c|c|}
\hline Population: & New Zealand White rabbits aged between $15-16$ weeks old \\
\hline Sample size: & $\begin{array}{l}24 \text { rabbits, both males and females who had been singly housed } \\
\text { from weaning: } \\
\text { - Males }(n=9) \\
\text { - } \quad \text { Females }(n=15)\end{array}$ \\
\hline Intervention details: &  \\
\hline
\end{tabular}




\begin{tabular}{|c|c|}
\hline & $\begin{array}{l}\text { to film four cages each } \\
\text { - Observations were split into three sections: } \\
\text { 1. Pre-trial observations (day } 1-3 \text { ) } \\
\text { Each rabbit acted as its own control to provide a baseline } \\
\text { behavioural assessment. } \\
\text { 2. Mirror trial observations (day } 4-10 \text { ) } \\
\text { An acrylic mirror was attached to the inside of the cage at } \\
\text { either the front (males } n=4 \text {; females } n=8 \text { ) or back (males } n \\
=5 ; \text { females } n=7 \text { ). This was randomly assigned on the left or } \\
\text { right of the cage. } \\
\text { 3. Post-trial observations (day } 11-13 \text { ) } \\
\text { Mirrors were removed and behaviour observed and } \\
\text { recorded for a further three days. } \\
\text { Observation schedules and behavioural assessment was } \\
\text { validated using a pilot study ( } 2 \text { day pre-trial, } 13 \text { day mirror } \\
\text { trial, } 7 \text { day post-trial) } \\
\text { Experimental timeline } \\
\text { - Study duration was } 13 \text { days }\end{array}$ \\
\hline Study design: & Randomised controlled trial \\
\hline Outcome studied: & $\begin{array}{l}\text { - Gender } \\
\text { - Percentage of time rabbits spent performing behaviours in } \\
\text { each behavioural category; inactive, eating and drinking, } \\
\text { body maintenance, mobility, stereotypy, investigatory } \\
\text { behaviour, comfort behaviour, mirror related behaviour, } \\
\text { time spent at the front and back of the cage }\end{array}$ \\
\hline $\begin{array}{l}\text { Main findings: } \\
\text { (relevant to PICO question): }\end{array}$ & $\begin{array}{l}\text { Gender } \\
\text { - Female rabbits spent less time on body maintenance than } \\
\text { males. There was a significant interaction between period } \\
\text { and gender }(\mathrm{P}=0.006) \text { with females and body maintenance, } \\
\text { showing a significant reduction in body maintenance at the } \\
\text { end of the trial compared to at the start } \\
\text { - Male and female rabbits spent on average } 1.2 \% \text { and } 0.8 \% \text { of } \\
\text { time, respectively, engaged in stereotypic behaviour ex. bar } \\
\text { biting and scratching at the floor of the cage } \\
\text { - Females showed a more consistent level of stereotypic } \\
\text { behaviour ex. bar biting and scratching at the floor of the } \\
\text { cage } \\
\text { Males showed an initial increase in stereotypic behaviour in } \\
\text { the pre-trial period. This decreased during the mirror period } \\
\text { and subsequently increased again in the post-trial period ( } P \\
=0.042) \\
\text { Males exhibited more investigatory behaviour than females, } \\
\text { although this was similar in pattern across both genders. } \\
\text { Investigatory behaviour increased during day } 1-2 \text { and then } \\
\text { subsequently declined over time } \\
\text { Females spent } 0.21 \% \text { of time sniffing, scratching and biting } \\
\text { the mirror }\end{array}$ \\
\hline
\end{tabular}




\begin{tabular}{|c|c|}
\hline & $\begin{array}{l}\text { Males spent } 0.15 \% \text { of time sniffing, scratching and biting the } \\
\text { mirror } \\
\text { - } \text { Females spent more time at the front of the cage in the } \\
\text { mirror trial period [31\%] than in the pre-trial period }[25 \%] \text { ( } P \\
=0.017) \\
\text { Behaviour performance } \\
\text { - } \\
\quad \text { All rabbits showed an increase in investigatory behaviour ( } P \\
\text { - } 0.042) \\
\text { All rabbits showed an increase in inactive behaviour over } \\
\text { time during the mirror-trial period }(P=0.014)\end{array}$ \\
\hline Limitations: & $\begin{array}{l}\text { - Investigatory behaviour declined over time. This could be } \\
\text { due to habituation to the mirror and the rabbit not receiving } \\
\text { confirmatory cues that the mirror image was another rabbit } \\
\text { - Could not distinguish between grooming (body } \\
\text { maintenance) and hair chewing (stress response/coping } \\
\text { mechanism) } \\
\text { - Different social strategies between males and females could } \\
\text { have affected the results. For example, males showed } \\
\text { increased investigatory behaviour at the start which was } \\
\text { more so than females. This may have contributed to stress if } \\
\text { the mirror image was perceived as a conspecific, and } \\
\text { therefore did not positively influence male rabbit welfare } \\
\text { It was not clear in the mirror trial period of the study if the } \\
\text { mirror positioning at either the front or back of the cage had } \\
\text { an effect on the rabbits behaviour }\end{array}$ \\
\hline
\end{tabular}

Dalle Zotte et al. (2008)

\begin{tabular}{|c|c|}
\hline Population: & $\begin{array}{l}\text { Pannon White rabbits aged } 5 \text { weeks old [sic], housed in a closed, } \\
\text { climatised rabbitry located in Kaposvár University, Hungary }\end{array}$ \\
\hline Sample size: & $\begin{array}{l}56 \text { [sic] rabbits split into two treatment groups: } \\
-\quad \text { Individually housed }(n=18) \\
-\quad \text { Group housed }(n=2,28 \text { rabbits in total, } 1 \text { group of } 12 \text { and } 1 \\
\text { group of } 16)\end{array}$ \\
\hline Intervention details: & $\begin{array}{l}\text { Experimental set up } \\
-\quad \text { Individual cages had a basic area of } 0.24 \mathrm{~m}^{2} \\
\text { - Individual cages had a stocking density of four cages per } \mathrm{m}^{2} \\
\text { - } \text { with one rabbit in each cage } \\
\text { - } \quad \text { Bwo group pens had an area of } 1 \mathrm{~m}^{2} \text { each } \\
\quad \text { parts; one side was covered in mirrors and one side was } \\
\text { covered in plastic panels } \\
\text { - Each side of all pens were separated by a swinging door } \\
\text { Further experimental detail } \\
\text { - Temperature was controlled at } 18^{\circ} \mathrm{C} \\
\text { - }\end{array}$ \\
\hline
\end{tabular}




\begin{tabular}{|c|c|}
\hline & $\begin{array}{l}\text { - Controlled lighting; } 16 \mathrm{~h} \text { light and } 8 \mathrm{~h} \text { dark per day } \\
\text { Methodology } \\
\text { - } \quad \text { Each treatment group was used as its own control } \\
-\quad \text { Random assignment of rabbits to pens } \\
-\quad 24 \mathrm{~h} \text { video recording performed twice weekly using infrared } \\
\text { cameras } \\
\text { - } \quad \text { Rabbits were not disturbed by human presence on the days } \\
\text { of recording } \\
\text { - The number of rabbits in each pen was counted every } 15 \\
\text { minutes, a total of } 96 \text { times per day } \\
\text { - Rabbit preference was assessed using a chi-squared test } \\
\text { Experimental timeline } \\
\text { - Study duration was } 6 \text { weeks } \\
\text { The study assessed stocking density, age and the effect of the time } \\
\text { of day on rabbits' preference for cages with or without a mirror. } \\
\text { Only data from individually housed rabbits will be used in this } \\
\text { knowledge summary as this is the only data relevant to the PICO. }\end{array}$ \\
\hline Study design: & Randomised controlled trial \\
\hline Outcome studied: & $\begin{array}{l}\text { Percentage of time spent in cages with mirrors including: } \\
\begin{aligned}- & \text { By age } \\
- & \text { By time (active [dark] vs. inactive [light] periods) } \\
- & \text { Overall (throughout the } 6 \text { week study duration) }\end{aligned}\end{array}$ \\
\hline $\begin{array}{l}\text { Main findings: } \\
\text { (relevant to PICO question): }\end{array}$ &  \\
\hline Limitations: & $\begin{array}{l}\text { - Preference for mirrors decreased as the rabbits got older. } \\
\text { However, this could be due to habituation to mirrors and } \\
\text { becoming more familiar with them in the environment. They } \\
\text { did not receive confirmatory cues that the mirror image was }\end{array}$ \\
\hline
\end{tabular}




\begin{tabular}{|l|l|}
\hline a conspecific so could have reduced interest \\
Sample was restricted as all rabbits were between 5 [sic] \\
and 11.5 weeks old. This could be potentially useful for the \\
hospitalisation of young rabbits, but would not be \\
generalisable to all rabbits as there was no indication of \\
mirror preference in older rabbits \\
$-\quad 6$ weeks in duration which is a longer amount of time than a \\
rabbit would generally be hospitalised for. Although there \\
may be some cases requiring longer hospitalisation \\
depending on the aetiology \\
Minimal enrichment in cages, which would be similar to that \\
of veterinary hospitalisation. Did rabbits prefer the mirror \\
because it was the only thing to interact with in the \\
environment? Was this down to curiosity instead of \\
recognising the mirror image as a conspecific? \\
The study involved pens which would be familiar to \\
laboratory rabbits but not to pet rabbits. It is an unnatural, \\
artificial environment and may therefore not be \\
generalisable wholly to domesticated rabbits \\
The information in this Knowledge Summary is taken directly \\
from the paper, it is unclear whether the rabbits were aged \\
5 or 5.5 weeks at the start of the study and 11 or 11.5 weeks \\
at the end respectively
\end{tabular}

\section{Appraisal, application and reflection}

All four studies addressed the effects of introducing a mirror to a solitary rabbits environment. It is important to note however, that the experimental timeline of all studies was generally longer than the average rabbit would spend hospitalised in veterinary practice.

Stress, fear and anxiety, as outlined in the PICO, were not directly measured although all four studies concluded that the presence of mirrors did in fact affect the subject rabbits behaviour. All studies measured behavioural responses, some of which could be indicative of a stressed, fearful or anxious rabbit.

As an example, fearful or anxious behaviour could include, but is not limited to, banging hind feet, darting and tachypnoea. Also, expression of stereotypies such as hair chewing has been suggested by previous studies to be indicative of stress due to social deprivation (Gunn \& Morton, 1995). Therefore, if a rabbit recognises a reflective mirror image of itself as another rabbit, this psychologically provides companionship. This was the case in female rabbits in Edgar \& Seaman (2010) as a significant interaction was observed. Female rabbits spent less time on body maintenance during the mirror trial. So, if addition of a mirror reduces social deprivation through provision of a conspecific image, this may lead to reduced exhibition of stress-related behaviour. Combined, this can improve rabbit welfare for short term periods of hospitalisation in a veterinary practice.

However, it is important to note that no differentiation between grooming (normal behaviour, generally considered positive) or hair chewing (stress-related behaviour) could be made during this study. Body maintenance was previously considered to be at elevated levels as each rabbit was used as its own control. The quality of this research was good due to it being a controlled trial, however, it was unclear from the methodology as to what constituted as a 'high level' of body maintenance prior to commencing behavioural observations. Regardless, body maintenance did significantly decrease after introduction of the mirror. This requires further investigation to be able to differentiate between normal and stress-related behaviour, grooming and hair chewing respectively. If both were previously at higher levels than normal, this could be 
indicative of stress anyway. Therefore, in relation to the PICO, presence of a mirror could reduce stressinduced over-grooming in female laboratory rabbits although further research is needed with a larger sample before this result can be applied to improving welfare and nursing care of hospitalised rabbits.

Taking this into consideration, both the variety of behaviour expressed and activity levels of rabbits housed with mirrors decreased over time also. Jones \& Phillips (2005) found rabbits were initially attracted to mirrors placed in their cages and spent time scrabbling at it, although this behaviour was observed less often over time. This study was very limited however as breed and treatment were confounded. Activity of rabbits also gradually decreased throughout the duration of the study in Reddi et al. (2011). It was suggested in both studies that this was because test rabbits did not receive confirmatory cues that the mirror was a conspecific and became less interested over time. They then became habituated to the mirror. It could therefore be suggested that, short term, a mirror could be beneficial and provide welfare advantages through environmental enrichment.

Similarly, mirror preference was suggested to decrease as the rabbits got older in Dalle Zotte et al. (2008). It was shown that rabbits were attracted to the mirror up to 11 weeks of age and the strongest preference was at the start of the study when the test rabbits were 5.5 [sic] weeks old. It is therefore unclear if the contributing factor towards mirror preference was the age of the rabbits or time spent with the mirror. In this paper, the ages of the rabbits do not add up, however the data was taken directly from the published study. In relation to the PICO, it is likely that younger rabbits show a stronger preference towards mirrors although all rabbits may be initially interested in them if introduced to their immediate environment. Further research could control rabbit age and offer a better insight into this finding.

On the other hand, Edgar \& Seaman (2010) contradicts the idea of habituation. Body maintenance continued to decrease over time. If this was stress-related behaviour, this strengthens the argument that mirrors have welfare advantages for rabbits, particularly those hospitalised short-term. However it was unclear from this study whether the position of the mirror within the cage also had an effect on rabbit behaviour. The fact stress-related body maintenance decreased significantly overall also suggests female test rabbits recognised the mirror image as a conspecific, subsequently improving welfare by psychological provision of companionship.

Another behaviour that decreased over time was investigatory behaviour, although some aspects of this may not be advantageous to welfare. For example, many of the studies above (Jones \& Phillips, 2005; Edgar \& Seaman, 2010; Reddi et al., 2011) stated in the initial experimental periods that investigatory behaviour increased, including sniffing and scratching at not only the mirror but vertical surfaces. In relation to the PICO, this strengthens the idea that a mirror could be considered a good and relatively cheap form of environmental enrichment in a veterinary setting for short term hospitalisation. However, before any clinical recommendations can be made, further research is needed into specific factors affecting this, particularly the initial response of male rabbits to mirrors.

It was suggested mirrors could be detrimental to male rabbits as vigilance and alertness increased initially, and more dramatically than females when introduced to a mirror (Edgar \& Seaman, 2010). The reasoning for this is not clear, however it is not unreasonable to suggest this could be due to competition for resources and territory with the mirrored image, especially being in a small and confined space. It is important to assess whether increased alertness also leads to increased levels of stress, fear and anxiety. It is important to investigate this before being able to recommend mirrors as nursing consideration for hospitalised male rabbits. Social factors behind these results need to be identified and assessed to avoid negative effects on welfare.

As well as reducing some behaviour, mirror presence has shown to be advantageous in improving some aspects of rabbit husbandry such as food consumption. Reddi et al. (2011) found the presence of mirrors increased rabbit bodyweight, food consumption and feeding efficiency. This was also found in Jones \& Phillips 
(2005) although hay intake was lower initially in this study. In relation to the PICO, it is important to consider these results could potentially be detrimental to rabbit welfare and increase stress, fear and anxiety. The presence of a mirror could increase food intake due to competition and resource rivalry with conspecific images. However, this does assume that rabbits are able to distinguish the mirror image from their own reflection and recognise it as another rabbit. It is assumed in all studies outlined above that rabbits are not capable of self-recognition. In a veterinary setting, mirrors could potentially aid inappetence in rabbits however further investigation into influencing factors, particularly in male rabbits, is needed before this can be recommended.

Considering all the above in relation to the PICO, there have been some benefits to rabbit welfare through using a mirror as environmental enrichment when assessed using behavioural observations. However, there have also been some indications that mirrors may be detrimental to the welfare of some rabbits. It is important to note that rabbits in a hospitalised environment will most likely be unwell or injured. They may prefer to be alone opposed to being housed with an unfamiliar conspecific image. This highlights the need for further, well controlled research studying both healthy and unwell rabbits, as well as a variety of treatments. There is also a need for larger sample sizes in future studies as this would add more confidence to any results before any practical application can be taken from existing research.

In conclusion, solitary rabbits are affected by the presence or absence of a mirror in their environment, but it is difficult to make definitive recommendations as there are large knowledge gaps currently in available published research.

\section{Methodology Section}

\begin{tabular}{|c|c|}
\hline \multicolumn{2}{|l|}{ Search Strategy } \\
\hline $\begin{array}{r}\text { Databases searched and dates } \\
\text { covered: }\end{array}$ & $\begin{array}{l}\text { A. PubMed via the NCBI website }(01 / 01 / 1973-31 / 12 / 2017) \\
\text { B. CAB Abstracts on the OVID interface }(1973-2017 \text { Week 40) }\end{array}$ \\
\hline Search terms: & $\begin{array}{l}\text { PubMed } \\
\text { 1. (rabbit OR rabbits OR lagomorph OR lagomorphs OR } \\
\text { "oryctolagus cunniculus" OR bunny OR bunnies OR hare OR } \\
\text { hares OR buck OR bucks OR doe OR does OR kittens OR kits } \\
\text { OR kitten) AND } \\
\text { 2. (mirror OR mirrors OR "reflecting glass") AND } \\
\text { 3. (stress OR stressed OR anxiety OR fear OR anxious OR fearful } \\
\text { OR worried OR nervous OR nervy OR panic OR panicked OR } \\
\text { fright OR frightened OR "tonic immobility" OR ti OR } \\
\text { immobility OR distressed OR distress OR scared OR scary OR } \\
\text { afraid OR behavioural OR pressure OR tension OR alarm OR } \\
\text { alarmed OR vigilant OR vigilance OR apprehension OR } \\
\text { apprehensive OR activity OR time OR budget OR "time } \\
\text { budget" OR nervousness OR stressful OR distress OR pain OR } \\
\text { painful OR "pain score" OR "pain scoring") } \\
\text { CAB Abstracts } \\
\text { 1. (rabbit or rabbits or lapine or lagomorph or lagomorphs or } \\
\text { bunny or bunnies or hare or hares or buck or bucks or doe } \\
\text { or kittens or kits or kittens or oryctolagus).mp. or exp } \\
\text { rabbits/ or exp oryctolagus cuniculus/ } \\
\text { 2. (mirror or mirrors or reflector or reflective or reflection or } \\
\text { 'reflecting glass' or 'reflective glass') } \\
\text { 3. (stress or stressed or stressful or distressed or anxiety or }\end{array}$ \\
\hline
\end{tabular}




\begin{tabular}{|l|l|l|}
\hline & $\begin{array}{l}\text { anxious or fear or fearful or fearfulness or worried or } \\
\text { nervous or nervy or nervousness or panic or panicked or } \\
\text { fright or frightened or scared or scary or afraid or alarmed } \\
\text { or alarm or apprehension or apprehensive or behaviour or } \\
\text { behaviour).mp. or exp stress/ or exp fearfulness/ or exp } \\
\text { anxiety/ }\end{array}$ \\
\hline Dates searches performed: 1 and 2 and 3 \\
\hline A. $05 / 12 / 2017$ \\
B. $16 / 10 / 2017$
\end{tabular}

\section{Exclusion / Inclusion Criteria}

Papers were screened by titles and abstracts initially upon whether they met the criteria to answer the knowledge summary question. Upon meeting the inclusion criteria, the full text article was obtained and assessed

\begin{tabular}{|l|l|l|}
\hline Exclusion: & - Irrelevant to PICO question \\
& - Paper subjects were not rabbits \\
& - No use of mirrors \\
& - Non-English publications \\
& - Duplicates \\
\hline Inclusion: & - Primary research papers \\
& - Peer reviewed journals \\
& - Rabbit subjects \\
& - Comparison of presence or absence of mirrors \\
& - Relevant to PICO question \\
& - Publications in English language \\
\hline
\end{tabular}

\begin{tabular}{|l|c|c|c|c|}
\hline \multicolumn{1}{|l|}{ Search Outcome } \\
\hline \multicolumn{1}{|c|}{ Database } & Number of results & $\begin{array}{c}\text { Excluded - not } \\
\text { relevant to PICO }\end{array}$ & $\begin{array}{c}\text { Excluded - } \\
\text { duplicates }\end{array}$ & $\begin{array}{c}\text { Total relevant } \\
\text { papers }\end{array}$ \\
\hline PubMed & 106 & 106 & 0 & 0 \\
\hline CAB Abstracts & 12 & 7 & $1 *$ & 4 \\
\hline Total relevant papers when duplicates removed & & 4 \\
\hline
\end{tabular}

*Paper was first presented at Proceedings of the 9th World Rabbit Congress, Verona, Italy, 10-13 June 2008

\section{CONFLICT OF INTEREST}

The author declares no conflict of interest. 


\section{REFERENCES}

1. Dalle Zotte, A., Princz, Z., Matics, Zs., Gerencsér, Zs., Metzger, Sz. \& Szendrö, Zs. (2008) Rabbits' preference for cages and pens with or without mirror. 9th World Rabbit Congress, June 10-13, 2008 Verona (Italy), pp. 1165-1170.

2. Davis, A.W. \& Hall, W.B. 1969. Cyclic change-over designs. Biometrika 56 (2), pp. 283-293. https://doi.org/10.1093/biomet/56.2.283

3. Edgar, J.L. \& Seaman, S.C. (2010) The effect of mirrors on the behaviour of singly housed male and female laboratory rabbits. Animal Welfare, 19 (4), pp. 461-471.

4. Gunn, D. \& Morton, D.B. (1995) Inventory of the behaviour of New Zealand White rabbits in laboratory cages. Applied Animal Behaviour Science, 45 (3-4), pp. 277-292.

https://doi.org/10.1016/0168-1591(95)00627-5

5. Jones, S.E. \& Phillips, C.J.C. (2005) The effects of mirrors on the welfare of caged rabbits. Animal Welfare, 14 (3), pp. 195-202.

6. McAfee, L.M. Mills, D.S. \& Cooper, J.J. (2002) The use of mirrors for the control of stereotypic weaving behaviour in the stabled horse. Applied Animal Behaviour Science, 78, pp. 159-173. http://dx.doi.org/10.1016/S0168-1591(02)00086-2

7. Parrott, R.F. Houpt, K.A. \& Misson, B.H. (1988) Modification of the responses of sheep to isolation stress by the use of mirror panels. Applied Animal Behaviour Science, 19 (3-4), pp. 331-338. https://doi.org/10.1016/0168-1591(88)90015-9

8. Piller, C.A.K. Stookey, J.M. \& Watts, J.M. (1999) Effects of mirror-image exposure on heart rate and movement of isolated heifers. Applied Animal Behaviour Science, 63 (2), pp. 93-102. http://dx.doi.org/10.1016/S0168-1591(99)00010-6

9. Reddi, A.K.G. Gouri, M.D. Raeshwari, Y.B. \& Ningaraju, K. (2011) Growth and performance changes in rabbits housed with or without a mirror. Mysore Journal of Agricultural Sciences, 45 (3), pp. 688-690.

10. Snedecor, G. \& Cochran, W.G. 1968. Statistical Methods. $6^{\text {th }}$ Edition. Iowa State University Press, lowa, USA. 


\section{EVIIDEFeE

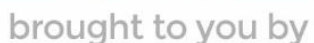 \\ RCVS KNOWLEDGE}

\section{Intellectual Property Rights}

Authors of Knowledge Summaries submitted to RCVS Knowledge for publication will retain copyright in their work, and will be required to grant RCVS Knowledge a non-exclusive license of the rights of copyright in the materials including but not limited to the right to publish, re-

publish, transmit, sell, distribute and otherwise use the materials in all languages and all media throughout the world, and to license or permit others to do so.

\section{Disclaimer}

Knowledge Summaries are a peer-reviewed article type which aims to answer a clinical question based on the best available current evidence. It does not override the responsibility

of the practitioner. Informed decisions should be made by considering such factors as individual clinical expertise and judgement along with patient's circumstances and owners' values. Knowledge Summaries are a resource to help inform and any opinions expressed within the Knowledge Summaries are the author's own and do not necessarily reflect the view of the RCVS Knowledge. Authors are responsible for the accuracy of the content. While the

Editor and Publisher believe that all content herein are in accord with current recommendations and practice at the time of publication, they accept no legal responsibility

for any errors or omissions, and make no warranty, express or implied, with respect to material contained within.

For further information please refer to our Terms of Use.

RCVS Knowledge is the independent charity associated with the Royal College of Veterinary Surgeons (RCVS). Our ambition is to become a global intermediary for evidence based veterinary knowledge by providing access to information

that is of immediate value to practicing veterinary professionals and directly contributes to evidence based clinical decision-making.

\section{https://www.veterinaryevidence.org/}

RCVS Knowledge is a registered Charity No. 230886.

Registered as a Company limited by guarantee in England and Wales No. 598443.

Registered Office: Belgravia House, 62-64 Horseferry Road, London SW1P 2AF

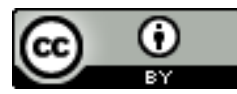

This work is licensed under a Creative Commons Attribution 4.0 International License 